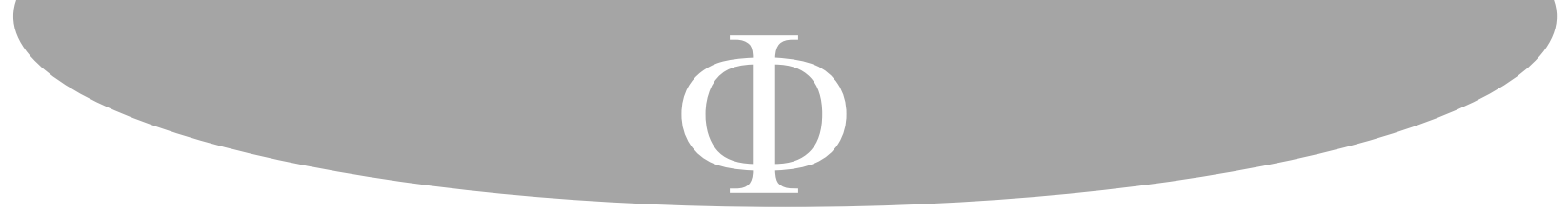

\title{
La lógica de don Quijote. El acontecer del pensamiento y del lenguaje en la lengua heredada* $^{*}$
}

Para citar este artículo: Molteni, Agostino y Solís Nova, David. «La lógica de don Quijote. El acontecer del pensamiento y del lenguaje en la lengua heredada». Franciscanum 176, Vol. 63

(2021): 1-26.

\section{Resumen}

El presente trabajo es un ensayo que se propone volver a pensar la lógica que engendra y mueve la obra de Miguel de Cervantes El ingenioso hidalgo don Quijote de la Mancha. Partiendo del planteamiento de que Cervantes y don Quijote son un mismo pensador, se trabajará sobre lo que se considera el principio de generación de esta novela, a saber, la noción del acontecer de la lengua heredada por medio de la elaboración de actos lingüísticos y de pensamiento compuestos. En este sentido, se presenta en este estudio la obra cervantina como una propuesta filosófica que podría replantear algunas tesis reiteradas y presupuestas de lo que, en variadas ocasiones, se entiende por la naturaleza del lenguaje y del pensamiento.

Palabras clave

Quijote, Cervantes, lenguaje, acontecimiento, pensamiento.

The Quixote's logic. The occurrence of the thinking and the language into an inherited mother tongue

\footnotetext{
${ }^{*}$ El presente artículo es producto de un proyecto interno regular de investigación de la Universidad Católica de la Santísima Concepción, titulado «El acontecimiento del pensamiento: dimensiones jurídicas-económicascívicas. Una propuesta filosófica y teológica». Código DINREG 01/2019.

** Doctor en Teología. Académico del Instituto de Teología de la Universidad Católica de la Santísima Concepción. ORCID: https://orcid.org/0000-0001-5392-0183. Contacto: amolteni@ucsc.cl.

${ }^{* * *}$ Doctor en Filosofía. Académico del Instituto de Teología de la Universidad Católica de la Santísima Concepción. ORCID: https://orcid.org/0000-0003-2462-8436. Contacto: dsolis@ucsc.cl.
} 


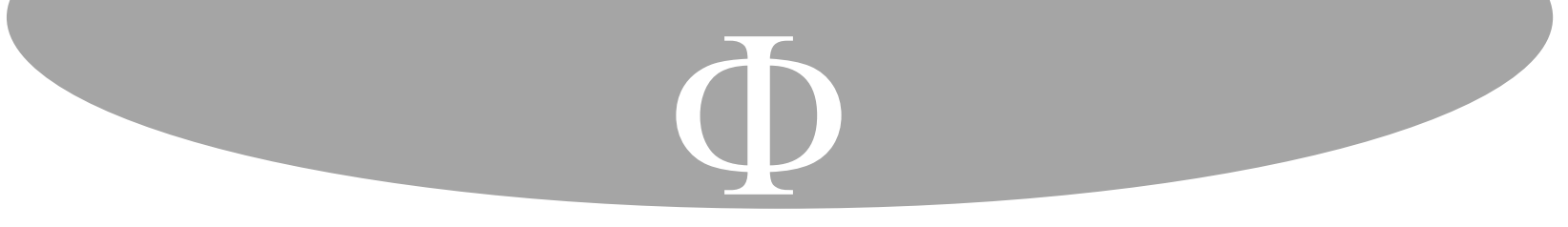

una excusa, desde el inicio de la obra, para justificar un pensamiento que anda por el mundo sin lógica ni sentido. El novelista reconoce aquí que su ensayar andante está lleno «de pensamientos varios», faltos «de toda erudición y doctrina», pero que tiene la competencia necesaria como para no andar «mendigando sentencias de filósofos, consejos de la Divina Escritura, fábulas de poetas, oraciones de retóricos, milagros de santos» ${ }^{8}$. Cervantes-Quijote siempre recalca su pensar competente y su juicio sano. Para cabalgar por el mundo se necesita caballo, armadura, siervo gordo y fiel, pero, sobre todo, se necesita componer actos lingüísticos de modo que «con palabras significantes, honestas y bien colocadas, salga vuestra oración y período sonoro y festivo» ${ }^{9}$, generando pensamientos que son «hijos del entendimiento» y que propicien, en alianza con otros, frases llenas de una lógica que pueda ser accesible a todos, es decir, universal: «dando a entender vuestros conceptos sin intricarlos y escurecerlos ${ }^{10}$.

Tal como Cervantes, recordado por Ortega y Gasset, «buscamos en nosotros, y solo en nosotros el origen de nuestros actos» ${ }^{11}$. En este sentido, no queremos ampararnos detrás de ninguna moderna «profesión» académica-erudita, tal como se amparaba el señor cura: «Y a vuestra merced, ¿quién le fía, señor cura? dijo don Quijote. Mi profesión -respondió el cura, que es de guardar secreto» ${ }^{12}$. Cuando el cura y el barbero-médico, sentados en lo alto de su episteme (su saber superior), consideran una locura e impertinencia que el hidalgo aconseje al rey sobre cómo batallar contra el «Turco», «El Caballero de la Triste Figura» no demora en defender su juicio competente:

El mío, señor rapador -dijo don Quijote-, no será impertinente, sino perteneciente (...) El mío ni es imposible ni disparatado, sino el más fácil, el más justo y el más mañero y breve que puede caber en pensamiento de arbitrante alguno ${ }^{13}$.

Reivindicamos, lo mismo que don Quijote, la posibilidad de una lectura que no necesita de erudición externa, sino del juicio competente sobre la experiencia de lectura de una obra como principal fuente de pensamiento. El nuestro será, al mismo tiempo, un ensayo de pensamiento com-puesto con el de Quijote-Cervantes que se oferta al público para ser juzgado, con beneficio de inventario, en su verdadero mérito.

El personaje Quijote es el mismo Cervantes en su acto de producir un acontecimiento lingüístico trabajando su lengua nativa. Refrenda el hidalgo la importancia de trabajar la lengua heredada cuando describe el intento de verter una poesía en lengua extranjera: «Con todo esto me parece que el traducir de una lengua en otra (...) es como quien mira los tapices flamencos por el revés, que aunque se ven las figuras, son llenas de hilos que las escurecen,

\footnotetext{
${ }^{8}$ Miguel de Cervantes, Don Quijote de la Mancha, 13.

${ }^{9}$ Miguel de Cervantes, Don Quijote de la Mancha, 13. Cursivas nuestras.

${ }^{10}$ Miguel de Cervantes, Don Quijote de la Mancha, 14.

${ }^{11}$ José Ortega y Gasset, Meditaciones de Quijote y otros ensayos, 131.

${ }^{12}$ Miguel de Cervantes, Don Quijote de la Mancha, 552.

${ }^{13}$ Miguel de Cervantes, Don Quijote de la Mancha, 551.
} 


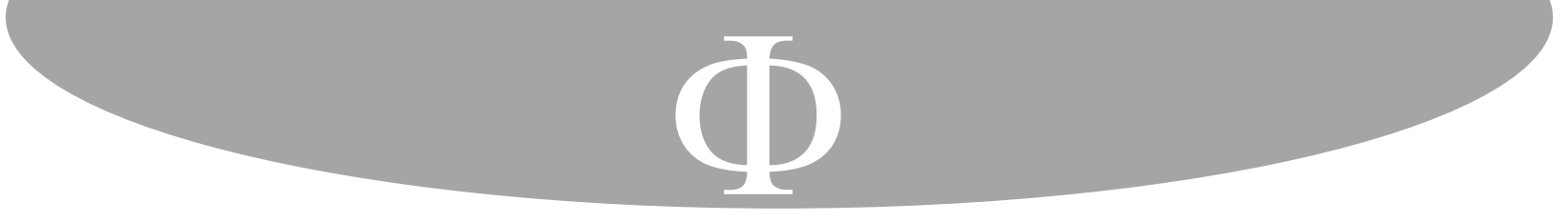

jurídicos, como un bautismo o la fundación de una ciudad ${ }^{54}$. Con estos actos lingüísticos los caballeros «eran conocidos por toda la redondez de la tierra» ${ }^{55}$. Si Sancho se comporta, al menos al principio de la aventura, como un filósofo ontológico, un metafísico de las cosasen-sí, de las esencias ya hechas, Quijote-Cervantes es la insurrección del acto lingüístico que desordena con su oferta los lugares comunes de una lengua sin cultivar y estéril, muerta en cuanto ya-hecha. Por eso, acusa a Sancho de ser un «bellaco villano, malmirado, descompuesto, ignorante, infacundo, deslenguado, atrevido, murmurador y maldiciente ${ }^{56}$, de ser un «bellaco descomulgado, que sin duda lo estás, pues has puesto lengua en la sin par Dulcinea» ${ }^{57}$. «Deslenguado» porque es una lengua «idiota», sin alianza, sin «composición» y fuera de la communio, y «maldiciente» porque reduce a la «jurídica» Dulcinea del Toboso a una ontológica Aldonza Lorenzo.

\subsection{El acto lingüístico-cívico, generador de universo}

En este punto, hay que señalar que la alianza engendrada por el acto lingüístico no es la de una pequeña secta aislada e insociable, no es un lenguaje privado. El lenguaje cuando es trabajado en una alianza siempre tiene frutos universales-cívicos que no excluyen que la «ciudad del mundo» se beneficie de ellos. Por ello, el «ingenioso hidalgo» no se inhibe de afirmar que la caballería andante y com-ponente es una ciencia, y una ciencia de las más altas, una ciencia cívica fundamentada en la justicia según el antiguo axioma: Iustitia est constans et perpetua voluntas ius suum cuique tribuendi:

Es una ciencia -replicó don Quijote- que encierra en sí todas o las más ciencias del mundo, a causa que el que la profesa ha de ser jurisperito, y saber las leyes de la justicia distributiva y conmutativa, para dar a cada uno lo que es suyo y lo que le conviene ${ }^{58}$.

El acto lingüístico o es cívico (justo) o no es acto lingüístico. Por ello, don Quijote no cambiaría a Sancho por una ciudad, porque la amistad entre ambos ya era la fundación de una ciudad: «Finalmente, yo no le trocaría con otro escudero, aunque me diesen de añadidura una ciudad» ${ }^{59}$.

Nos atreveríamos a decir que un lenguaje es confiable cuando puede ser capaz de ser público y universal. Esto es lo que comprueba don Quijote cuando ve el fruto de su andante composición:

Grande es la prerrogativa que encierra en sí la andante caballería, pues hace conocido y famoso al que la profesa por todos los términos de la tierra; si no, mire vuestra merced, señor don Antonio, que hasta los muchachos de esta ciudad, sin nunca haberme visto, me conocen ${ }^{60}$.

\footnotetext{
54 «Tú eres Pedro y sobre esta Piedra edificaré mi Iglesia» (Mt 16, 18)

${ }^{55}$ Miguel de Cervantes, Don Quijote de la Mancha, 172.

${ }^{56}$ Miguel de Cervantes, Don Quijote de la Mancha, 478. Cursivas nuestras.

${ }^{57}$ Miguel de Cervantes, Don Quijote de la Mancha, 307. Cursivas nuestras.

${ }^{58}$ Miguel de Cervantes, Don Quijote de la Mancha, 682. Cursivas nuestras.

${ }^{59}$ Miguel de Cervantes, Don Quijote de la Mancha, 803.

${ }^{60}$ Miguel de Cervantes, Don Quijote de la Mancha, 1024.
} 


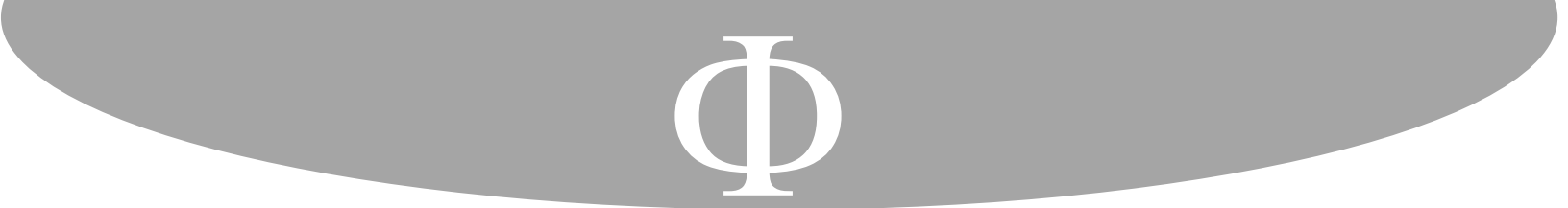

en los libros: «La tal historia es del más gustoso y menos perjudicial entretenimiento que hasta ahora se haya visto, porque en toda ella no se descubre, ni por semejas, una palabra deshonesta ni un pensamiento menos que católico» ${ }^{78}$.

\subsection{Sintetizando}

Sintetizando lo que nos parece la lección de Cervantes-Quijote, se puede decir que para él el lenguaje es un producto meta-físico, pues trans-forma la materia prima de la lengua en producción sobre-natural, como el campesino trans-forma el trigo y la uva en pan y vino, en productos meta-físicos, pues no existen en la naturaleza. El lenguaje (aquello común y público), es siempre un trabajo filosófico, sin necesidad de ir a la academia de filosofía. Don Quijote lo reafirma cuando se pronuncia respecto a la dimensión económica-enriquecedora de la lengua por parte del acto del lenguaje:

Erutar, Sancho, quiere decir «regoldar», y este es uno de los más torpes vocablos que tiene la lengua castellana, aunque es muy significativo; y, así, la gente curiosa se ha acogido al latín, y al regoldar dice erutar, y a los regüeldos, erutaciones, y cuando algunos no entienden estos términos, importa poco, que el uso los irá introduciendo con el tiempo, que con facilidad se entiendan; y esto es enriquecer la lengua, sobre quien tiene poder el vulgo y el uso ${ }^{79}$.

En este sentido, todos los hombres pueden ser parte de esta alianza, todos pueden remontar la lengua heredada y componer con otros un acontecimiento del pensamiento y del lenguaje. El acto lingüístico no puede quedar encerrado en un relativismo ni en un pequeño mundo interior, sino que tiene vocación de ofertarse a todos sin exclusiones, no por un afán de filantropía, sino porque surgió de la alianza y el trabajo com-puesto con otros y necesita ser nutrido una y otra vez por otros actos lingüísticos que puedan invertir su trabajo en una alianza recíproca y universalmente beneficiosa. La universalidad que surge del acto cívico no puede abandonar nunca sus intereses económicos. Todos los sujetos ganan en la medida que se trabaja con otros y no contra otros. Esto es lo que don Quijote llamaría enriquecer la lengua y el pensamiento, un tesoro cívico:

Una de las cosas -dijo a esta sazón don Quijote- que más debe de dar contento a un hombre virtuoso y eminente es verse, viviendo, andar con buen nombre por las lenguas de las gentes, impreso y en estampa. Dije con buen nombre, porque siendo al contrario, ninguna muerte se le igualara ${ }^{80}$.

\section{Sugerencias cervantinas-quijotescas para una renovación del lenguaje}

El drama y fracaso del «Caballero de la Triste Figura», como ya habíamos señalado, es que muy pocas veces es aceptada su afabilidad, porque la mayoría de los sujetos con los que se encuentra siguen pensando en un mundo de cosas ya hechas, donde los molinos tienen

\footnotetext{
${ }^{78}$ Miguel de Cervantes, Don Quijote de la Mancha, 572.

${ }^{79}$ Miguel de Cervantes, Don Quijote de la Mancha, 872. Cursivas nuestras.

${ }^{80}$ Miguel de Cervantes, Don Quijote de la Mancha, 568. Cursivas nuestras.
} 


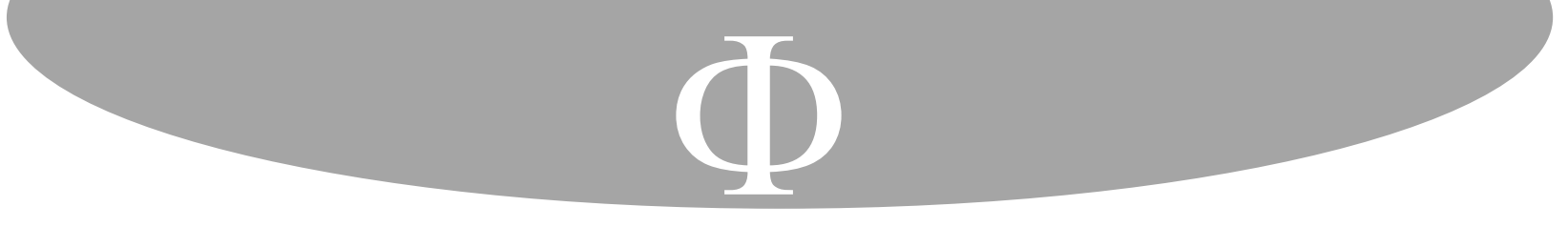

una esencia de molinos y son siempre lo que ya eran. Desde este punto de vista sustancialista, los molinos no pueden ser sino molinos de viento. Para el Quijote los molinos pueden acontecer de otra manera, los molinos pueden ser imputados, en una batalla leal, de acuerdo con sus actos y de acuerdo a si sus actos-frutos son beneficiosos o no. De esa manera, un bolígrafo puede acontecer como un arma homicida en manos de un asesino o una ballesta puede acontecer como un objeto de decoración en manos de un coleccionista. «El Caballero de la Triste Figura» lo recalca: "Así, eso que a ti te parece bacía de barbero me parece a mí el yelmo de Mambrino y a otro le parecerá otra cosa» ${ }^{81}$. Sancho y el hidalgo caballero componen actos lingüísticos que los dejan satisfechos mutuamente y en los que ya vislumbran beneficios universales: «baciyelmo» ${ }^{82}$ es el nuevo acto-fruto metafísico que han heredado al mundo generado a partir de su trabajo de pensamiento.

En este sentido, se puede afirmar que la lógica del Quijote es la misma que la de Cristo, la lógica que sostiene que el árbol se conoce por los frutos y que una higuera sin higos es sombra o leña para el fuego. Si no da frutos de higuera no es una higuera, no se la puede imputar como una higuera. Nélida Piñon sostiene: «El carácter insurgente del verbo de Cervantes niega la noción de que vivimos en un universo estable» ${ }^{83}$. Por otro lado, CervantesQuijote no es un nominalista que piense que a los universales les falta toda existencia, existencia hecha solo de objetos individuales, donde los universales serían meramente nombres. Ni tampoco se puede decir que Quijote-Cervantes «cree» de modo fideísta, con un acto de fe irracional, en la realidad de los nombres tomándolos por «cosas». El fideísmo es siempre sustancialista, es el de Sancho, antes de comprender del todo a su señor don Quijote, cuando escuchándolo hablar de ejércitos «cree» que esta sea su ontología-sustancia-esencia: «Con tanto ahínco afirmaba don Quijote que eran ejércitos, que Sancho lo vino a creer» ${ }^{84}$. Mientras el Quijote imputa a las ovejas y carneros como ejércitos, Sancho los cree fideístamente- hechos como sustancia-esencia de ejércitos. Aquí está el nuevo inicio de la lógica del Quijote-Cervantes y que contiene muchas más riquezas que el corriente discurso explicativo del Quijote como un hidalgo que ha perdido la razón.

En este punto, podemos decir que el orden del lenguaje de Quijote-Cervantes no es de profundidades, sino de «superficies» como ha hecho notar, justamente, Ortega y Gasset ${ }^{85}$. Sin embargo, es claro que es una superficie «jurídica», es decir, imputable por sus actos. Diríamos, por nuestra parte, más bien no es hombre de esencias, sino de actos generados en una alianza. El mismo Ortega dirá más adelante: «Para un mediterráneo no es lo más

\footnotetext{
${ }^{81}$ Miguel de Cervantes, Don Quijote de la Mancha, 237.

${ }^{82}$ Miguel de Cervantes, Don Quijote de la Mancha, 465. Leo Spitzer recalca que Cervantes «con la creación de baciyelmo se libera de las limitaciones del lenguaje». Leo Spitzer, «El perspectivismo lingüístico del Quijote», Centro virtual Cervantes, Instituto Cervantes, consultada en octubre 11, 2020, https://cvc.cervantes.es/literatura/quijote_antologia/spitzer.htm

83 Nélida Piñon, «Dulcinea», en Don Quijote por el mundo, ed. Instituto Cervantes (Barcelona: Galaxia Gutenberg, 2005), 113.

${ }^{84}$ Miguel de Cervantes, Don Quijote de la Mancha, 157. Cursivas nuestras.

${ }^{85}$ José Ortega y Gasset, Meditaciones de Quijote y otros ensayos, 72.
} 


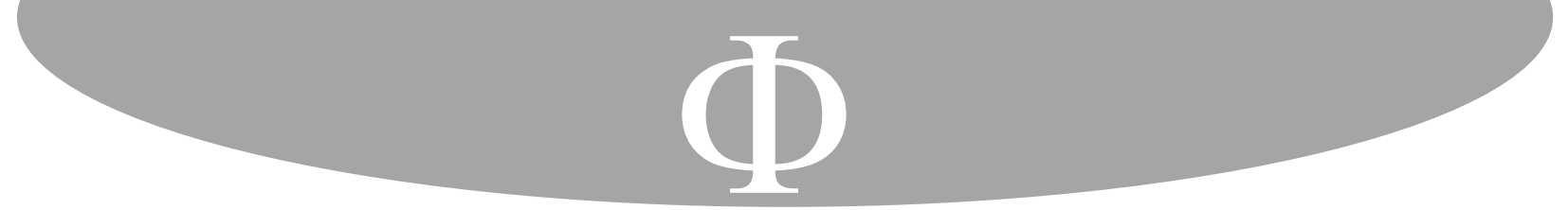

alcanzaron que todas se encaminaban a ofrecimiento y requiebros; y, como no usadas a semejante lenguaje, mirábanle y admirábanse y parecíales otro hombre de los que se usaban $^{91}$.

Más bien, agregaríamos, ellas no le entendían porque, efectivamente, pensaban en griego, en conceptos, ideas y sustancias. No estaban disponibles a ese lenguaje que no era vehículo de una cosa ya hecha, sino que se proponía como una oferta que exigía de ellas el trabajo para componer un acontecimiento de pensamiento inédito. Se podría decir lo mismo en sentido inverso, que el hidalgo no comprendía un lenguaje que venía ya pre-formado y pre-dispuesto: «El lenguaje, no entendido de las señoras [las mujeres del partido, las prostitutas], y el mal talle de nuestro caballero acrecentaba en ellas la risa y en él el enojo» ${ }^{92}$. Don Quijote no quiere comunicar ni que le comuniquen nada, ya que sólo se puede comunicar lo que ya está hecho. Al contrario, el gusto de don Quijote es componer un lenguaje, con socios y no con esclavos sumisos a ideas ya hechas. Por eso, insistimos diciendo que el acto lingüístico del Quijote-Cervantes es propiciatorio de relaciones productivas (negocios), es el único lenguaje «práctico», propiamente «pragmático». En este sentido, la composición del acto lingüístico y de pensamiento es el único que nos puede sacar de un permanente relativismo y perspectivismo, porque es un acto compuesto con vocación cívica y universal. Como es un acto público, se hereda para que otros lo trabajen y puedan verificar si realmente puede dar frutos universales y beneficiosos, urbi et orbi.

El pensamiento del caballero andante, nos atreveríamos a decir, es la antítesis de la filosofía de Parménides y la de todos sus seguidores. Don Quijote de la Mancha es el antiParménides. En efecto, es Parménides quien nos ha hablado de una sabiduría venida desde lo alto (una vez más la «episteme»), revelada a algunos iniciados, quienes ya no siguen el camino trillado de la opinión de los hombres comunes y corrientes ${ }^{93}$. Es un saber que está atado con las fuertes cadenas de una justicia, una necesidad y un hado ya hechos, ontológicos $^{94}$. El Quijote es más bien obrero de una ley jurídica y cívica, y no esclavo de leyes y hados naturales y esencializados. Conocemos, además, su repulsa a todo tipo de cadenas y a todo tipo de jaulas. Este saber, al cual el sabio-iniciado parmenídeo debe someterse, nos dice que «lo que es» está ya hecho, como una esfera bien redonda porque, en efecto, ¿cómo podría nacer, componer y acontecer si el ser es ingenito, inmóvil, sin comienzo ni fin e ilimitado ? $^{95}$. Muy por el contrario, el hidalgo va de camino a co-instituir historias nuevas, a componer actos lingüísticos y a generar con otros una riqueza de pensamiento. No podría su promesa de caballero detenerse a un punto en un ser ya hecho. El Quijote no podría ser sumiso ante este ser revelado que impone forzosamente su método.

\footnotetext{
${ }^{91}$ Miguel de Cervantes, Don Quijote de la Mancha, 140. Cursivas nuestras.

${ }^{92}$ Miguel de Cervantes, Don Quijote de la Mancha, 38.

${ }^{93}$ Geoffrey Kirk y John Raven, Los filósofos presocráticos (Madrid: Gredos, 1981), 374-375.

${ }^{94}$ Geoffrey Kirk y John Raven, Los filósofos presocráticos, 383 y 386.

95 Geoffrey Kirk y John Raven, Los filósofos presocráticos, 382-383.
} 


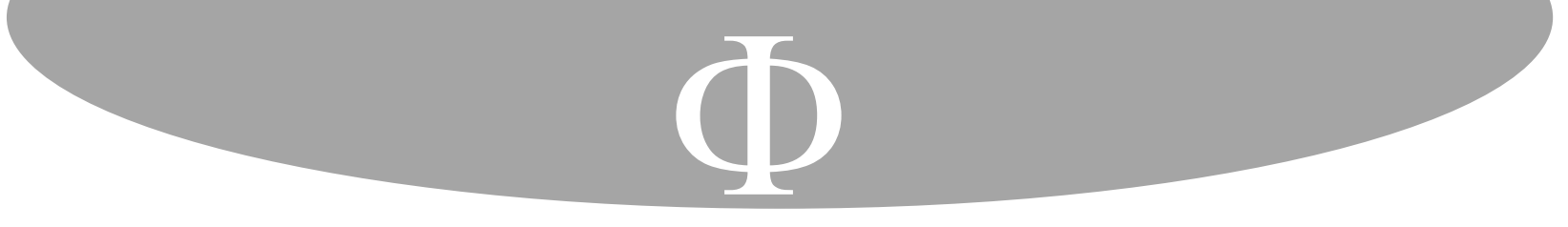

Es más, si el poema de Parménides enseña que lo mismo es el pensar y el ser, si las mismas «poderosas cadenas» que sujetan al ser sujetan también al pensar ${ }^{96}$, tal como dice Breton, la «revelación del ser» parmenídea es «el momento de la más grande restricción ejercitada sobre el "es". La limitación es esencial a la forma sujeto. El sujeto debe definirse por una especie de infinita sujeción» ${ }^{97}$. Al contrario, don Quijote escribirá una clase muy distinta de poemas y compondrá una clase muy distinta de pensamientos, por ser él otro tipo de sujeto, alguien que se autoriza por sí solo.

En este punto, podemos afirmar que solo a través de un trabajo semper condendum, hecho de actos lingüísticos compuestos, se puede escapar de «ser hablado» por la lengua, de ser pensado por un pensamiento patológico (una lógica deprimida) en la que el individuo es inhibido en su autoridad de competencia, en su capacidad legislativa de lenguaje. Un discurso autoritario impide que el individuo sea la fuente del derecho (primum ius), fuente de civitas com-puesta con otros individuos en el pensamiento y en el lenguaje. «El Quijote de la Mancha» luchará contra esto y dejará su vida en ello, pues «por la libertad, así como por la honra, se puede y debe aventurar la vida» ${ }^{98}$.

Este es el sentido de los llamados «encantadores» que encierran al caballero en una jaula, en un sistema de pensamiento prefijado y no compuesto ${ }^{99}$. Hemos ya señalado como la gran mayoría de los personajes del Quijote no sólo no comprendió, sino que no quiso comprender sus ofertas beneficiosas de alianzas que sus actos linguiísticos querían propiciar. Por ejemplo, lo vemos en la incapacidad sustancialista de Dorotea de acontecer como otra, de re-nacer, cuando el caballero lanza su oferta de alianza: «Quienquiera que os dijo, valeroso Caballero de la Triste Figura, que yo me había mudado y trocado de mi ser, no os dijo lo cierto, porque la misma que ayer fui me soy hoy ${ }^{100}$. De igual forma, no podía acontecer su amada Dulcinea como tal, porque todos se había acostumbrado a pensarla como Aldonza Lorenzo. Es esta la principal incapacidad en el pensar, la principal enfermedad del lenguaje o «encantamiento»: que lo que ha sido ya deba seguir siendo hoy. Esta persistencia de una realidad ya hecha es lo que inunda de tristeza al hidalgo: «Pensativo a demás iba don Quijote por su camino adelante, considerando la mala burla que le habían hecho los encantadores volviendo a su señora Dulcinea en la mala figura de la aldeana» ${ }^{101}$. Pese a todo, el pensamiento andante del caballero no se detiene porque «tenía en poco a los encantos y a los encantadores» ${ }^{102}$, ya que no pueden quitarle su pensamiento andante y su ley dispuesta a componer con otros un acontecer lingüístico: «Bien podrán los encantadores quitarme la ventura; pero el esfuerzo y el ánimo, será imposible» ${ }^{103}$.

\footnotetext{
${ }^{96}$ Geoffrey Kirk y John Raven, Los filósofos presocráticos, 377-388.

97 Stanislas Breton, «Est-Je suis. Parménide ou Moïse», Revue Philosophique de Louvain 2, Vol. 98 (2000): 243. Traducción propia.

${ }^{98}$ Miguel de Cervantes, Don Quijote de la Mancha, 984-985.

${ }^{99}$ Miguel de Cervantes, Don Quijote de la Mancha, 482.

${ }^{100}$ Miguel de Cervantes, Don Quijote de la Mancha, 387.

${ }^{101}$ Miguel de Cervantes, Don Quijote de la Mancha, 623.

${ }^{102}$ Miguel de Cervantes, Don Quijote de la Mancha, 659.

${ }^{103}$ Miguel de Cervantes, Don Quijote de la Mancha, 677.
} 


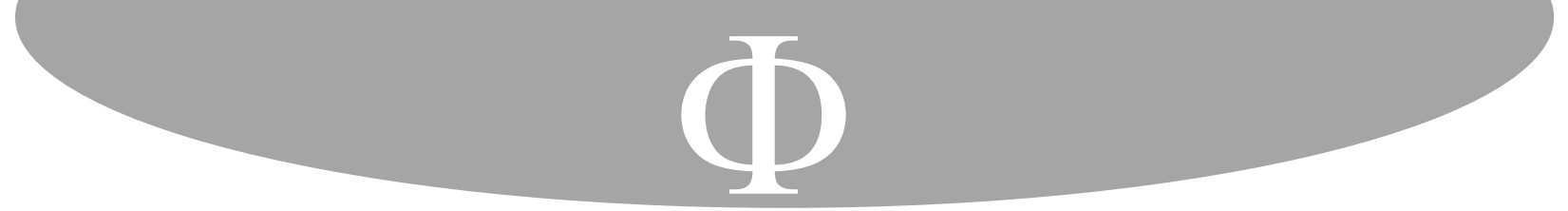

El pensamiento-lenguaje de Cervantes-Quijote, para usar la expresión de Ortega y Gasset, nos permite con sus aventuras «quebrar como un cristal la opresora, insistente realidad» ${ }^{104}$, la opresión de las cosas-en-sí a las cuales adecuarse con sometimiento, quebrar la opresora realidad para que acontezca lo «imprevisto, lo impensado» ${ }^{105}$, es decir, lo no pensado en la lengua en cuanto todavía está a la espera del cultivo de sus herederos para que la hagan acontecer. Creemos que el pensamiento que mueve al Quijote es un pensamientoacto lingüístico en movimiento y capaz de mover la inmovilidad del ser-ya-hecho: «Yo, señores -respondió don Quijote -, os lo agradezco, pero no puedo detenerme un punto, porque pensamientos y sucesos tristes me hacen parecer descortés y caminar más que de paso» ${ }^{106}$. Es lo que escribió María Zambrano del pensamiento y de la poesía en la vida española:

Toda filosofía es polémica en su esencia y lo que triunfó con Parménides triunfó frente a algo. Triunfó conquistándose la realidad indefinida definiéndola como ser; ser que es unidad, identidad consigo mismo, inmutabilidad residente más allá de las apariencias contradictorias del mundo sensible del movimiento; ser captable únicamente por una mirada intelectual llamada noein y que es «idea». Ser ideal, verdadero, en contraposición a la fluyente, movediza, confusa y dispersa heterogeneidad que es el encuentro primero de toda vida. (...) el pensamiento de Parménides alcanzó el poder en su sometimiento de la realidad al ser, mejor dicho, de lo que simplemente encontramos, al ser ideal captado en la idea y cuyo rasgo fundamental es la identidad de la cual se deriva la permanencia, la inmutabilidad. Lo demás, el movimiento, el cambio, los colores y la luz, las pasiones que desgarran el corazón del hombre, son «lo otro», lo que ha quedado fuera del $\operatorname{ser}^{107}$.

Por eso, María Zambrano aboga por la necesidad de un pensamiento poético bien distinto de la inimputable filosofía ontológica griego-parmenídea:

Y mientras tanto, de otro lado el poeta seguía su vía de desgarramiento, crucificado en las apariencias, en las adoradas apariencias, de las que no sabe ni quiere desprenderse, apegado a su mundo sensible: al tiempo, al cambio y a las cosas que más cambian, cual son los sentimientos y pasiones humanas, a lo irracional sin medida, íbamos a decir sin remedio, porque esto es sin remedio ni curación posible. La Filosofía fue además alguien se hizo plenamente cargo de ello- curación, consuelo y remedio de la melancolía inmensa del vivir entre fantasmas, sombras y espejismos. Pero la poesía no quiso curarse... ${ }^{108}$.

El ingenioso hidalgo tampoco quiso curarse. Don Quijote no quiso curarse de ser fiel al acontecer del pensamiento, de la disponibilidad a una posible novedad de lo imprevisto e

\footnotetext{
104 José Ortega y Gasset, Meditaciones de Quijote y otros ensayos, 116.

105 José Ortega y Gasset, Meditaciones de Quijote y otros ensayos, 116. «En la novela de Cervantes las cosas se representan no por lo que ellas son en sí, sino sólo en cuanto objeto de nuestro lenguaje o de nuestro pensamiento». Leo Spitzer, «El perspectivismo lingüístico del Quijote».

${ }^{106}$ Miguel de Cervantes, Don Quijote de la Mancha, 1057. Cursivas nuestras.

${ }^{107}$ María Zambrano, Pensamiento y poesía en la vida española (México: La casa de España,1939), 8-9.

${ }_{108}$ María Zambrano, Pensamiento y poesía en la vida española, 11.
} 


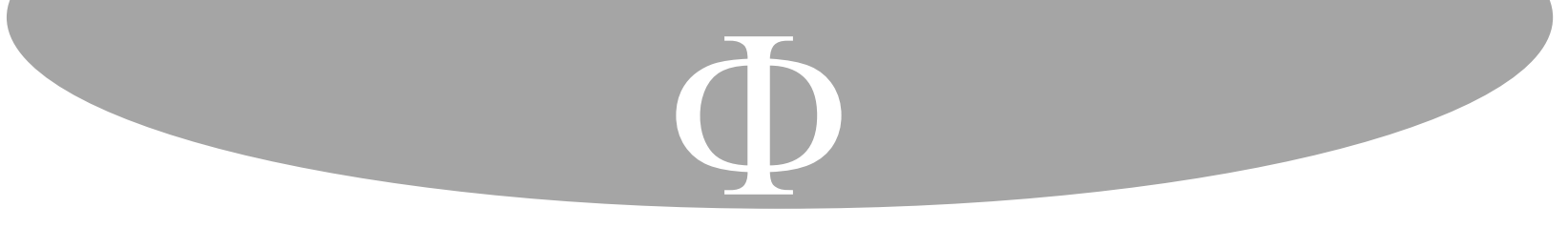

En este sentido, Cervantes quiso en su Quijote forjar un lenguaje fecundo en frutos de pensamiento, aquel «del decoro del que habla, con mucha propiedad y entendimiento» ${ }^{114}$. El afán de encontrar actualidad en los clásicos de la literatura (y del pensamiento) se entiende, a menudo, como análisis y comparaciones sociológicas en relación con los tiempos que corren. El Cervantes-Quijote es más que actual, es moderno. Si es pertinente decir que «el individuo no puede orientarse en el universo sino a través de su raza» ${ }^{115}$, por la raza de su «lengua», el Quijote es moderno porque quiere ser juzgado-imputado por su pensamiento que acontece como acto lingüístico (jurídico, económico y cívico) heredando con beneficio de inventario, abonando (haciendo bueno) con trabajo de re-capacitación, re-habilitación la materia prima de su lengua. El Quijote-Cervantes es moderno porque ha ofrecido un acontecimiento lingüístico y del pensamiento en su obra ofertado a todos como hijo de su entendimiento. Es moderno porque es productor de una lengua que él ha trabajado, elaborando todo el ingenio, la experiencia, la raza, la sabiduría que en ella había para que aconteciera todo esto renovado en un presente. Y, en este sentido, es moderno también, amigo del presente, pues promulga la figura del laico como el sujeto jurídico que no está sometido a una «epi-steme» superior, la episteme de una lengua ya hecha con pretensiones de inmovilizar, sin posibilidad de reinicio, una manera de pensar.

En todos los tiempos la lengua es como una ciudad permanentemente bombardeada por teorías que obstaculizan que esta pueda ser trabajada en un acto lingüístico, por ejemplo, las teorías sustancialistas que consideran que la lengua es un nombrar de cosas y las que consideran que la lengua es sólo un medio de expresión y comunicación de un sujeto a otro. En la primera visión, la lengua se somete a una teoría estática sobre la esencia de las cosas y, en la segunda, la lengua es sólo un vehículo para transmitir esa teoría estática. Tales bombardeos teóricos constantes son vicios lógicos propiamente «pathos- lógicos», en cuanto soportan el grave peso de una lengua rígida y estéril.

Con ayuda del Cervantes-Quijote creemos que es posible juzgar la cizaña que hace estéril una lengua, en cuanto no es una lengua de la cual brotan actos lingüísticos, sino que es una simple lengua de cosa ya hechas y de definiciones ya mandatadas. El pensamiento en lengua española presentado en el Quijote por Cervantes ofrece la posibilidad de escapar de la jaula de un discurso del «amo» o «universitario» (como dice Lacan) ${ }^{116}$, la misma jaula en la que intentó encerrar a don Quijote la episteme de los profesionales del saber -el médico y el cura- y el resto de los encantadores. La jaula de un discurso que es pensamiento y lenguaje dictatorialmente ontológico parmenídeo, por el cual «el ser es», por el cual al lenguaje y a la lengua no les queda más que ser lo que ya eran.

\footnotetext{
${ }^{114}$ Miguel de Cervantes, Don Quijote de la Mancha, 64-65.

115 José Ortega y Gasset, Meditaciones de Quijote y otros ensayos, 91.

116 Jaques Lacan, «Seminario 17», consultada en octubre 16, 2020, https://www.bibliopsi.org/docs/lacan/20\%20Seminario\%2017.pdf; Jaques Lacan, Psicoanálisis Radiofonía \& Televisión (Barcelona: Anagrama, 1993).
} 


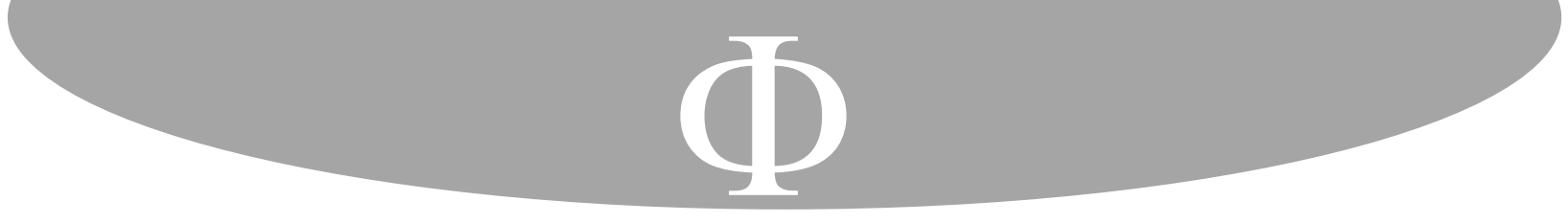

Ortega y Gasset, José. Meditaciones de Quijote y otros ensayos. Madrid: Alianza, 2014.

Péguy, Charles. Euvres en prose complètes I. Paris: Gallimard, 1987.

Péguy, Charles. Euvres en prose complètes III. Paris: Gallimard, 1992.

Platón, Diálogos II. Madrid: Gredos, 1992.

Spitzer, Leo. «El perspectivismo lingüístico del Quijote», Centro virtual Cervantes, Instituto $\begin{array}{lllll}\text { Cervantes. } & \text { Consultada } & 2020 .\end{array}$

https://cvc.cervantes.es/literatura/quijote_antologia/spitzer.htm

Wilde, Oscar. El retrato de Dorian Grey. Miami: El Cid Editor, 2009.

Zambrano, María. España, sueño y verdad. Barcelona: Edhasa, 2002.

Zambrano, María. Pensamiento y poesía en la vida española. México: La casa de España,1939.

Enviado: 26 de octubre de 2020 Aceptado: 27 de noviembre de 2020 